\title{
ENGINEERING JOURTIAL
}

Article

\section{Approach to Identifying Black Spots Based on Potential Saving in Accident Costs}

\author{
Huy Huu Nguyen ${ }^{1, a, *}$, Pichai Taneerananon ${ }^{2, b}$, and Paramet Luathep ${ }^{2, c}$ \\ 1 EU-Asia Road Safety Centre of Excellence (RoSCoE), Department of Civil Engineering, Prince of \\ Songkla University, Hat Yai, Songkla 90112, Thailand \\ 2 Centre for Road Safety Research, Department of Civil Engineering, Prince of Songkla University, Hat Yai, \\ Songkla 90112, Thailand \\ E-mail: ahuycongtrinh@yahoo.com (Corresponding author), bbreathislife@yahoo.com, \\ cparamet007@hotmail.com
}

\begin{abstract}
In improving road safety, the identification of black spots based on potential saving in accident costs is an attempt to make the selection of black spots to treat out of the identified ones. This selection is based on a new approach in which safety potential is employed as a key parameter which has a dual function of identification and prioritization. With this approach, it is possible to find black spots where safety improvement measures are expected to have the greatest economical effectiveness. Therefore, the approach may be a practically suitable tool for developing countries in road traffic accident reduction effort. This paper intends to introduce the new approach to identify road accident black spots in detail. First, the evolution of criteria for black spot identification is reviewed. What follows is an analytical framework for identifying black spots based on potential saving in accident costs. Finally, a particular case of practical implementation is enclosed in order to illustrate the approach.
\end{abstract}

Keywords: SAPO, safety potential, hot spots, black spots, hazardous locations.

ENGINEERING JOURNAL Volume 20 Issue 2

Received 19 May 2015

Accepted 26 August 2015

Published 18 May 2016

Online at http://www.engj.org/

DOI:10.4186/ej.2016.20.2.109 


\section{Introduction}

Road safety improvement entails black spot treatment whose first step is the identification of black spots. Therefore, the accuracy in identifying black spots has great effect on the effectiveness of the results of black spot analysis and treatment (Elvik, 2006) [1]. However, the identification of black spots can be done with various methods each of which employs a different set of criteria. And, difference in criteria leads to difference in accuracy in identification. As a result, the question of which criteria to select for the process of identification so as to have the optimal results has been of great concern.

Another thing is that the selection of suitable criteria is different from country to country. Unlike developed countries, developing ones are facing financial difficulties in improving road safety [2]. That means it is impracticable for developing countries to treat all identified black spots. Accordingly, it is necessary to establish an approach which can facilitate not only the identification but also prioritization of black spots. Such approach requires a parameter with dual function of both identifying and prioritizing black spots. The approach to identifying black spots based on potential saving in accident costs employs safety potential as a key parameter can meet this requirement. With such approach, it is possible to shorten the list of the identified black spots and make the suitable selection of the black spots the treatment of which can be economically effective.

\section{Evolution of Criteria for Identifying Black Spots}

This section chronologically reviews the developments of black spot identification methods in which different accident parameters are employed as identification criteria. Over time, new parameters have been added so as to optimize the efficiency and the flexibility of black spot treatment. Such gradual addition depicts the evolution of criteria for black spot identification which is illustrated by the following researches.

Norden et al. (1956), Rudy (1962), and Morin (1967) used the method of industrial statistical quality control for highway safety [3-5]. In this method upper control limit of accident count and upper control limit of accident rate were used as criteria in identifying black spots. Such black spot identification method employed only two parameters: the observed accident number and the traffic volume.

Tamburri and Smith (1970) introduced the notion of the safety index which is actually a combined criterion of accident number and accident severity [6]. The establishment of this criterion led to the development of a method of black spot identification which initially incorporated the accident-severitybased prioritization in identifying black spots. As a result, accident severity was employed as a new parameter in black spot identification.

Jorgensen (1972) introduced a new method which employed two new factors: (1) mean of expected accident counts calculated by multivariable model, and (2) the observed accident number [7]. The identification of black spots is based on the difference between the expected number and the observed number of accidents. As a result, expected number of accident was employed as a new parameter in black spot identification.

Taylor and Thompson (1977) suggested that a hazardousness index be defined for each road section or spot as a weighted sum of a mix of accident frequency, rate, severity, volume-to-capacity ratio, sight distance, conflicts, erratic maneuvers, and driver expectancy [8]. There is general recognition here that there are clues to hazardousness other than accident occurrence. As a result, hazardousness index was considered a new aspect in black spot identification.

McGuigan $(1981,1982)$ suggests that for each road section and intersection one calculate the difference between the actual number of accidents and the expected number of accidents for such a class of road or intersection given the same traffic $[9,10]$. This suggestion furthered the accuracy of black spot identification by using accident rate rather than accident frequency.

Higle and Witkowski (1988) used the Empirical Bayes approach and focused on the identification of road sections with unusually large accident rates [11]. These two authors showed how the probability distribution function of the accident rate at a specific road section can be obtained. A road section is then said to be hazardous if the probability that its accident rate exceeds a certain value is sufficiently large. With this point of view, Higle and Witkowski (1988) initialized why and how to minimize the inaccuracy of actual accident rate. In other words, the correction of actual accident rate was introduced.

Overgaard Madsen (2005) discussed in detail criteria for identifying black spots [12]. This author proposed that an adequate definition of a black spot should satisfy these four criteria: 
(1) It should control for random fluctuations in the number of accidents.

(2) It should account for as many of the factors that are known to influence road safety as possible.

(3) It should identify sites at which fatal and serious injury accidents are over-represented.

(4) It should identify sites at which local risk factors related to road design and traffic control make a substantial contribution to accidents.

With this proposal, the author managed to systematize the aspects of and the corresponding criteria for black spot identification suggested by previous researches. Such systematization drew up a set of guidelines which can enable proper selection of criteria for black spot identification.

Elvik (2008a) practically evaluated criteria used to identify black spots and provided the list of the five most common ones as follows [13]:

(1) Upper tail accident count,

(2) Upper tail accident rate,

(3) Upper tail accident count and high accident rate,

(4) Upper tail expected number of accident (Empirical Bayes estimate), and

(5) Upper tail Empirical Bayes (EB) dispersion criterion.

The author also concluded that of the five criteria, EB estimates of safety is the most reliable.

Nguyen et al. (2013) proposed a black spot safety management approach called safety-potential-based black spot management, which relies on expected number of accidents as an additional parameter in identifying true black spots. That means in its identification of black spots, safety-potential-based approach makes use of three parameters: recorded number of accidents, expected number of accidents, and critical value [14].

For all the above mentioned methods the availability of crash data is a significant requirement for identifying hazardous locations or black spots. However, in case of roads with poor accident data sets or no accident records, Habibian et al. (2011) proposed an approach to identify and rank black spots independent of the accident records. This approach suggests that a road be investigated by decomposing it first into different elements, and then into safety factors corresponding to each type of element (straight segments, horizontal and vertical curves, tunnels, intersections, and side road land use, etc.). The relative contribution of the elements to the safety of a road spot is determined using the Analytical Hierarchy Process (AHP) via a system of weights suggested by an expert panel. Subject to a consistency test of the expert responses, AHP determines the weight of elements. In an independent survey, roads are audited and ranked with respect to their elements. The weighted sum of these ranks is used to calculate a safety index for a road spot. Road spots with the lowest values of safety index are identified as the most hazardous road locations or black spots [15].

Mesbah and Habibian (2006) suggested that AHP method can be used to investigate the importance of factors influencing road safety [16]. Temrungsie et al. (2015) conducted an AHP-based study to determine the importance of factors affecting accidents in Thailand. This study has indicates that the factor which has the strongest impacts on accidents is the safety management factor including law enforcement and road users' knowledge of road rules [17].

\section{Approach to Identifying Black Spots based on Potential Saving in Accident Costs}

\subsection{Analytical Framework}

The identification of black spots based on potential saving in accident costs or safety potential (SAPO) can be divided into five steps as shown in Fig. 1.

\subsubsection{Step 1-Data collection and statistical analysis of accidents}

The data collection is supposed to come up with the quantitative statistics of the following three sets of data:

- Accident data by severity and location;

- Accident unit cost by accident severity;

- AADT or ADT and Basic accident cost rate (bACR) of the road networks.

The process of collecting such data may pose these two common issues - (1) the inaccessibility of bACR, and (2) the decision as to which crash period to select. However, there are applicable solutions for both of the two issues. 
- If the data on bACR is insufficient, a specific percentile (e.g. 15\%) of the overall distribution of the accident cost rates can be used [18].

- The crash period of three to five years is the best choice for the sake of data validity and reliability. Actually, a number of experts of road safety present the support of this point of view.

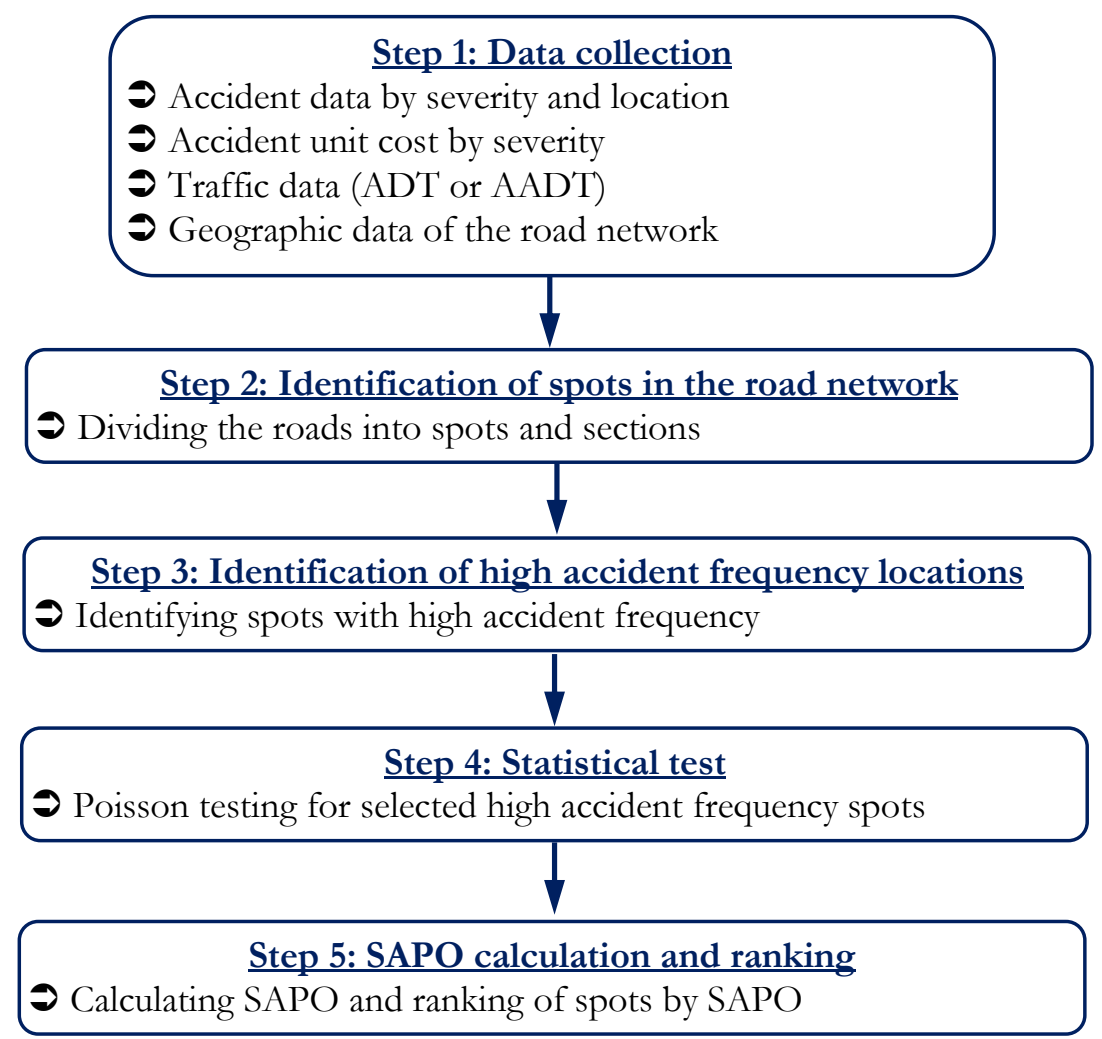

Fig. 1. Reference framework diagram for identifying black spots based on potential saving in accident costs.

First, Elvik (2008b) claims that the length of the period used to identify black spots varies from 1 year to 5 years, a period of 3 years is used frequently [19]. Next, research by Cheng and Washington (2005) shows that the gain in the accuracy of black spot identification obtained by using a longer period of three years is marginal and declines rapidly as the length of the period is increased. There is little point in using a longer period than 5 years [20]. Additionally, LTNZ (2004) stressed out that a 3-year crash period could be used in heavily trafficked networks or areas where road changes are recent or ongoing [21]. A three-to-fiveyear period is preferred because:

- It is long enough to provide a sufficient number of crashes for meaningful results;

- It is short enough to limit the number of traffic and environmental changes that may bias results;

- It helps remove statistical fluctuation and reduce the impact of the regression-to-the-mean effect;

- It provides a consistent base for before and after comparisons.

\subsubsection{Step 2-Identification of spots by dividing the roads into sections and spots}

In the road safety engineering, the following different calculation models should be distinguished: (1) sections with similar alignment - models for certain road sections, and (2) transitions (single elements) models for spots.

According to Bast and Sétra (2005), there are two possible ways of dividing a road into sections and spots [18].

(1) Dividing the road into sections and spots on basis of the network structure 
This method of dividing is appropriate if a visualization of the accident occurrence on the road network (accident map) is not available or the accident occurrence is to be analyzed in interaction with other influencing parameters (e.g. road improvement standard, accessibility, traffic) in the road network.

(2) Dividing the road into sections and spots on basis of the accident occurrence

This method of dividing appropriate if a visualization of the accident occurrence is available and no other section demarcations are required on the basis of a joint consideration of various influencing parameters.

Ogden (1994), SEMCOG (1997), and TRB (2009) pointed out that spots should be defined to include the area of influence of the features in question [22-24]. For example, driver behavior can be influenced as far as 150 metres from a curve and 76 metres from an intersection (or further with severe congestion and queuing). Considering an influence area of at least 150 metres from both ends of a non-intersection spot location also helps ensure that a larger share of relevant crashes are properly identified, given typical uncertainties and errors in reporting crash position.

\subsubsection{Step 3-Identifying high accident frequency locations}

This step is aimed to identify the list of high accident frequency locations within the sample of locations established according to the dividing of the road into sections and spots as in Step 2. Such identification is based on the threshold value of observed numbers of injury accidents at every location in the sample in three consecutive years. The simplest way to select the threshold value for the sample is the following (Eq. (1)):

$$
\text { Threshold_value }=\max [\bar{x}, m]
$$

in which: $\quad \bar{x} \quad:$ the average value, and

$$
\mathrm{m} \quad: \text { the median value of the sample. }
$$

Any site with observed number of accidents higher than the threshold value is listed as a high accident frequency location. Sites that have more accidents than the mean plus one standard deviation $(\bar{x}+\sigma)$ should be the first to be single out for further consideration [25].

\subsubsection{Step 4-Statistical tests}

As crashes are rare and random, the number of reported accidents will change from one time period to another even if the expected average crash frequency remains the same [26]. To make sure that the spots identified as hazardous are not merely the result of random variation in accident counts, statistical tests are performed. The test consists of the comparison of the observed number of accidents with the expected number of accidents of that spot and the determination of the importance of the deviation by calculating the confidence interval of the observed values (Poisson law) [18].

Furthermore, the Poisson test can be used to determine whether a recent increase in accidents at a site was due to random fluctuation only [26]. What is mentioned above can be illustrated in the following example.

Table 1. Accidents for four year at a site.

\begin{tabular}{cc}
\hline Year & Observed accidents \\
\hline 2010 & 3 \\
\hline 2011 & 2 \\
\hline 2012 & 2 \\
\hline 2013 & 5 \\
\hline
\end{tabular}

Example: Propose that the injury accident figures observed at a site are as shown in Table 1.

The statistics show that the observed numbers of accidents fluctuated over the years with the sharp increase in the year 2013 as a noticeable case (see Table 1). This fact poses the question of whether such increase was due to random variation only. To answer this question it is necessary to calculate the 
confidence interval of the observed accidents and then consider the relation between the number of observed accidents of the year 2013 and the confidence interval.

- If the interval encompasses the observed values, there is no random variation. That means the change in the number of the observed accidents is a real one.

- If the interval does not encompass the observed values, there is a random variation. That means the change in the number of the observed accidents is not a completely real one.

Specifically, for the case of this example, the confidence level of $95 \%$ corresponds to the confidence interval of from 0.76 to 5.24 accidents as shown in Table 2 . This means that accidents may systematically happen in the range of $1-6$. In other words, the increase in 2013 is real because the corresponding observed number is 5 .

Table 2. Calculation of $95 \%$ confidence interval.

\begin{tabular}{|c|c|c|}
\hline \multicolumn{3}{|c|}{ Calculation of confidence interval of statistical sample in 4 years perioc } \\
\hline \multicolumn{2}{|c|}{ Long-term average } & 3.00 \\
\hline \multicolumn{2}{|c|}{ Standard deviation } & 1.4142 \\
\hline \multicolumn{2}{|c|}{ Confidence level $95 \%$} & 2.2436 \\
\hline \multirow{2}{*}{$95 \%$ Confidence interval } & Minimum value & 0.76 \\
\hline & Maximum value & 5.24 \\
\hline
\end{tabular}

The cumulative probability that there are more than 6 accidents with long-term average value $(\mu=3.0)$ is calculated by Poisson formula as follows [27].

$$
P(X \geq x, \mu)=1-P(X \prec x, \mu)=\sum_{k=0}^{x-1} \frac{e^{-\mu} \mu^{k}}{k !}=P(X \geq 7,3.0)=0.0335=3.35 \%
$$

Here, probability of seven or more accidents with the long-term average being 3.0 is 0.0335 or $3.35 \%$. This indicates that the random variation of accident count at the site is 3.35 percent.

Exact calculations of random variation in accident count at a spot require a complicated process. In order to simplify the process, the calculation method which is based on the confidence interval and the year-based numbers of observed accidents is a suitable choice. This method enables the quantitative estimation of the random variation in accident counts at a given spot. On the basis of this estimation the high accident frequency locations can be detected more easily.

\subsubsection{Step 5-Calculation of safety potential and ranking of spots}

This step is aimed to (1) calculate the safety potential of the spots identified in Step 3 and verified in Step 4, and (2) rank these spots according to the established safety potential.

The calculation of the safety potential is done using the following accident parameters: annual average accident cost, accident density, accident cost density, accident rate, accident cost rate, and basic accident cost rate as shown in Eqs. (3) to (9) in Table 3. Then, the spots of the road network are ranked on the basis of the magnitude of the safety potential. Such ranking is of great use to further detailed studies so as to determine possible improvement measures. The higher the safety potential, the more societal benefits can be expected from improvements to the roads [14, 28].

Briefly, the analytical framework for identifying black spots based on potential saving in accident costs or safety potential is described as in Fig. 1. 
Table 3. Accident parameters for determination of safety potential of spots [14, 28].

\begin{tabular}{|c|c|}
\hline Parameters & Formulas \\
\hline $\mathrm{AC}_{\mathrm{a}}$ & $\begin{array}{l}\qquad A C_{a}=\frac{\sum_{i=1}^{4} n A\left(c_{i}\right) \times M C A\left(c_{i}\right)}{t} \\
\text { Where: } \\
A C_{a} \quad: \text { annual average accident cost [USD/year] } \\
n A\left(c_{i}\right) \quad: \text { number of accidents of specific accident category } c_{i}, \text { in } \mathrm{t} \geq 3 \text { years } \\
M C A\left(c_{i}\right): \text { mean cost per accident of accident category } c_{i}[\mathrm{USD} / \text { accident] } \\
\mathrm{t} \quad: \text { period of time under review [years] }\end{array}$ \\
\hline $\mathrm{AD}$ & \begin{tabular}{ll} 
& \multicolumn{1}{c}{$A D=n A / t$} \\
Where: & \\
$A D \quad:$ accident density \\
$n A$ & $:$ number of accidents \\
$\mathrm{t}$ & $:$ time period [years] \\
\end{tabular} \\
\hline ACD & $\begin{array}{l}\text { WCD }=A C /(1000 \cdot t) \\
\text { Where: } \\
A C D \quad: \text { accident cost density }[1000 \mathrm{USD} / \text { year] } \\
A C \quad: \text { accident cost } \\
\mathrm{t} \quad: \text { time period [years] }\end{array}$ \\
\hline AR & $\begin{array}{l}\quad A R=10^{6} \cdot n A /(365 \cdot A A D T \cdot t) \\
\text { Where: } \\
A R \quad: \text { accident rate } \\
n A \quad: \text { number of accidents } \\
A A D T: \text { average annual daily traffic } \\
\mathrm{t} \quad: \text { time period [years] }\end{array}$ \\
\hline ACR & $\begin{array}{l}\text { ACR }=1000 \cdot A C /(365 \cdot A A D T \cdot t) \\
\text { Where: } \\
A C R \quad: \text { accident cost rate }[\mathrm{USD} / 1000 . \mathrm{veh}] \\
A C \quad: \text { accident cost } \\
A A D T: \text { average annual daily traffic } \\
\mathrm{t} \quad: \text { time period [years] }\end{array}$ \\
\hline $\mathrm{bACD}$ & $\begin{array}{l}\qquad b A C D=\frac{b A C R \times A D T \times 365}{10^{6}} \\
\text { Where: } \\
b A C D \quad: \text { basic accident cost density }[1000 \mathrm{USD} / \text { year }] \\
b A C R \quad: \text { basic accident cost rate } \\
A D T \quad: \text { average daily traffic }\end{array}$ \\
\hline SAPO & $\begin{array}{l}\quad S A P O=A C D-b A C D \\
\text { Where: } \\
S A P O: \text { safety potential }[1000 \mathrm{USD} / \text { year }] \\
A C D \quad: \text { accident cost density } \\
b A C D \quad: \text { basic accident cost density }\end{array}$ \\
\hline bACR & $\begin{array}{l}\text { The basic accident cost rate (bACR) can be defined for many different types } \\
\text { of roads and intersections which are derived from the detailed assessment of } \\
\text { existing accident cost rates [18]. }\end{array}$ \\
\hline
\end{tabular}

\subsection{Practical implementation}

In order to provide a detailed description of analysis steps in identifying black spots based on potential saving in accident costs or safety potential, an urban district named Phu-Nhuan in Ho Chi Minh City (HCMC) was selected as the study area. Before identifying the expected locations, some amount of a priori knowledge about the safety performance of the road network is required. This knowledge was compiled in an extensive data set describing various characteristics of accident distribution profiles as shown in Table 4. 
This data set was compiled for all types of urban roads over a period of 3 years and contains 40 different parameters related to accident occurrence, such as accident type, severity, and roadway conditions. The set represents a source of a priori knowledge base required for accidents mapping and the estimating of basic accident cost rate.

Table 4. Normative values of various accident characteristics.

\begin{tabular}{|c|c|c|c|c|}
\hline \multicolumn{5}{|c|}{ ACCIDENTS ON URBAN ROADS IN PHU-NHUAN DISTRICT, HO CHI MINH CITY, VIETNAM } \\
\hline Categories & Description & Quantity & Percent & \\
\hline \multirow{6}{*}{ 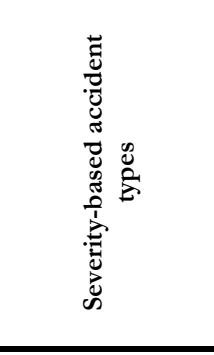 } & AS1: Accidents with fatalities & 59 & $11.11 \%$ & \\
\hline & AS2: Accident with seriously injured & 307 & $57.82 \%$ & \\
\hline & AS3: Accident with slightly injured & 123 & $23.16 \%$ & \\
\hline & AS4: Accident with serious material damage & 5 & $0.94 \%$ & \\
\hline & AS5: Accident with material damage but with driving while intoxicated & 33 & $6.21 \%$ & \\
\hline & $\begin{array}{l}\text { AS6: Accident with material damage but without driving while } \\
\text { intoxicated }\end{array}$ & 4 & $0.75 \%$ & $100.00 \%$ \\
\hline \multirow{4}{*}{ 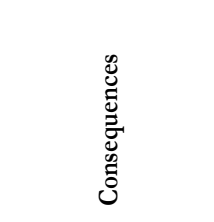 } & Persons killed & 61 & $\mathrm{~N} / \mathrm{A}$ & \\
\hline & Persons injured & 672 & $\mathrm{~N} / \mathrm{A}$ & \\
\hline & Property damage with motorcycles & 943 & $\mathrm{~N} / \mathrm{A}$ & \\
\hline & Property damage without motorcycles & 186 & $\mathrm{~N} / \mathrm{A}$ & \\
\hline \multirow{4}{*}{ 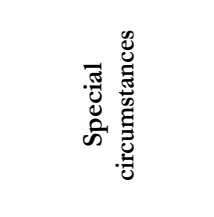 } & Accidents with motorcycles are involved & 493 & $92.84 \%$ & $493 / 531$ \\
\hline & Accidents with bicycles are involved & 19 & $3.58 \%$ & $19 / 531$ \\
\hline & Accidents with pedestrians are involved & 46 & $8.66 \%$ & $46 / 531$ \\
\hline & Drink-driving accidents & 18 & $3.39 \%$ & $18 / 531$ \\
\hline \multirow{2}{*}{$\begin{array}{l}\text { Motorcycle-related } \\
\text { accident types }\end{array}$} & Motorcycle Accidents (caused by a motorcycle) & 432 & $81.36 \%$ & \\
\hline & Non-Motorcycle accidents (not caused by a motorcycle) & 99 & $18.64 \%$ & $100.00 \%$ \\
\hline \multirow{2}{*}{$\begin{array}{l}\text { Intersection-related } \\
\text { accident types }\end{array}$} & Intersection accidents (occurring at intersections) & 216 & $40.68 \%$ & \\
\hline & $\begin{array}{l}\text { Non-intersection accidents (occurring at a location other than } \\
\text { intersections) }\end{array}$ & 315 & $59.32 \%$ & $100.00 \%$ \\
\hline \multirow{2}{*}{$\begin{array}{l}\text { Time-based } \\
\text { accident types }\end{array}$} & Day-Time Accidents & 167 & $31.45 \%$ & \\
\hline & Night-Time Accidents & 364 & $68.55 \%$ & $100.00 \%$ \\
\hline \multirow{7}{*}{ 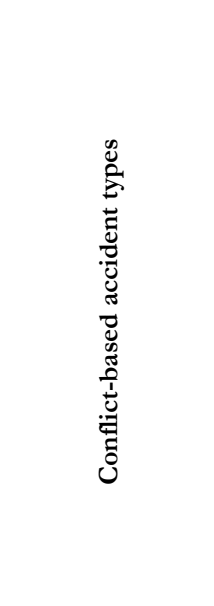 } & $\begin{array}{l}\text { AC1: Driving Accidents (caused by loss control of the vehicle without } \\
\text { influence of other road users) }\end{array}$ & 30 & $5.65 \%$ & \\
\hline & $\begin{array}{l}\text { AC2: Turn-off Accidents (caused by a collision between moving } \\
\text { vehicles with other road users during a turn-off maneuver at } \\
\text { junctions) }\end{array}$ & 18 & $3.39 \%$ & \\
\hline & $\begin{array}{l}\text { AC3: Turn-into/Crossing Accident (caused by a collision between } \\
\text { moving vehicles with other road users having right of way during } \\
\text { a turn-into or crossing maneuver at junctions) }\end{array}$ & 138 & $25.99 \%$ & \\
\hline & $\begin{array}{l}\text { AC4: Accident With Crossing Pedestrian (caused by a collision } \\
\text { between a vehicle and a pedestrian crossing the road) }\end{array}$ & 49 & $9.23 \%$ & \\
\hline & $\begin{array}{l}\text { AC5: Accident With Parked Vehicle (caused by a collision between } \\
\text { moving vehicles with parked or stopped ones) }\end{array}$ & 16 & $3.01 \%$ & \\
\hline & $\begin{array}{l}\text { AC6: Accident with Longitudinal Direction (caused by a collision } \\
\text { between road users which drive in the same or opposite } \\
\text { direction) }\end{array}$ & 254 & $47.83 \%$ & \\
\hline & AC7: Other Accidents (not classified as any of the six types above) & 26 & $4.90 \%$ & $100.00 \%$ \\
\hline \multirow{3}{*}{ 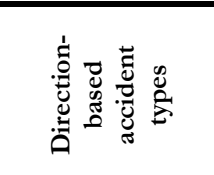 } & $\begin{array}{l}\text { AD1: Collision between a moving vehicle with a vehicle that has just } \\
\text { started, is stopped, or parked }\end{array}$ & 9 & $1.69 \%$ & \\
\hline & AD2: Collision with a vehicle which drivers in front or has stopped & 113 & $21.28 \%$ & \\
\hline & AD3: Collision with a vehicle which drives parallel in the same direction & 42 & $7.91 \%$ & \\
\hline
\end{tabular}




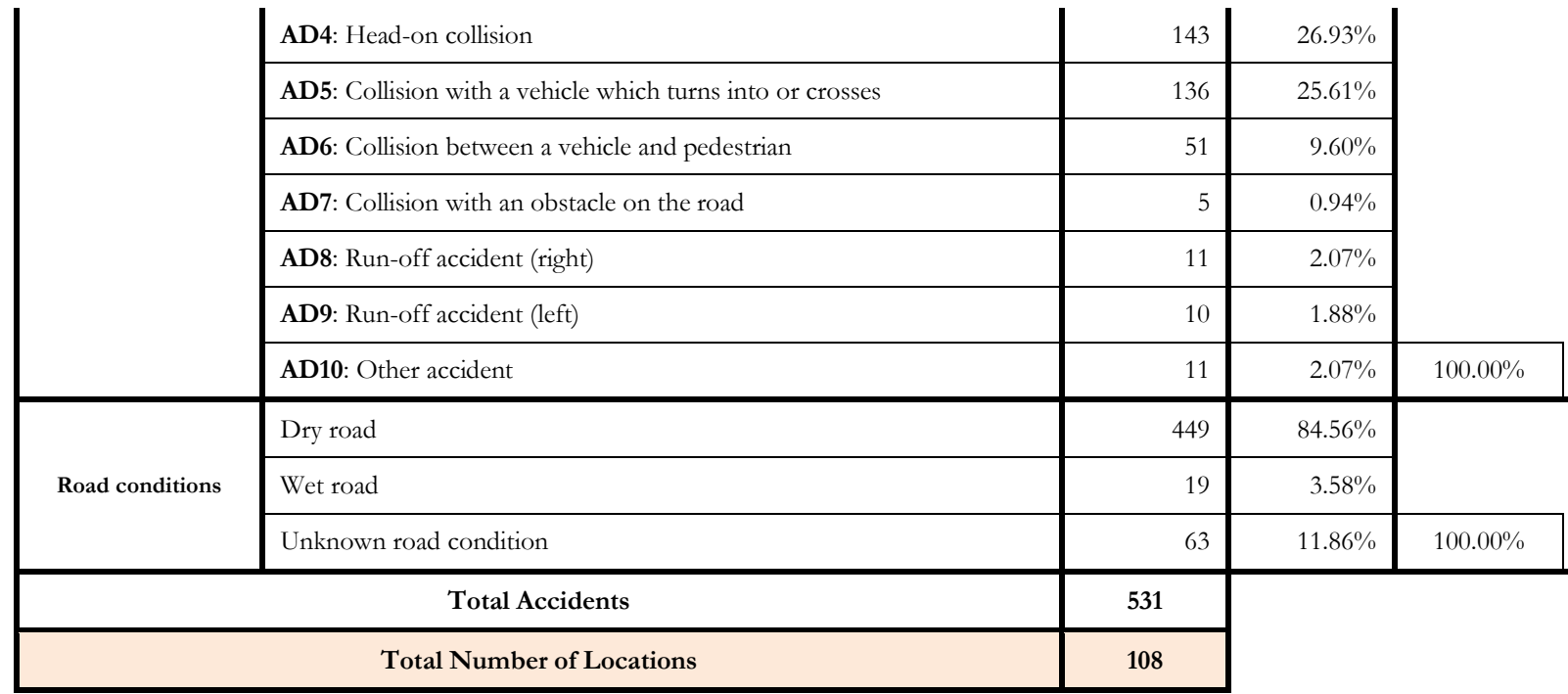

\subsubsection{Stage 1-Accident data collection, statistical analysis, and mapping accidents}

Accident data collection and statistical analysis are the prerequisites for identifying black spots based on safety potential. However, it was only possible to access a limited amount of raw road accident data from the local authorities. Accordingly, by means of the analysis of the raw data, a set of intermediate input data was established - the 3-year Accident Pin Board (3-year APB) of the period 2009-2011 as shown in Fig. 2. The 3-year APB serves as an accident map with the detailed information in the following aspects:

- Location of accidents;

- Severity-based accident types;

- Conflict-based accident types;

- Special accident circumstances.

The locations of accidents are marked on the GIS-based map. The severity-based accidents are marked by pin sizes. The conflict-based accidents are marked by pin colors. Special circumstances of accidents are marked by colored triangles as shown in the legends of 3-year APB.

\subsubsection{Stage 2-Dividing the road network into sections and spots based on 3-year APB}

This step was aimed to identify locations where accidents have clustered with the visual support of the 3 year APB. Collectively, 108 accident spots were identified, and coded, and the total number of accidents at each of which was also determined. Such intermediate data not only established the divisions of the road network into sections and spots but also facilitates the identification of high accident frequency locations in the next step.

\subsubsection{Stage 3-Identifying high accident frequency locations}

To identify high accident frequency locations, the data on 108 identified accident spots in Step 2 are statistically processed. As a result, the statistical sample of number of injury accidents in three years is established. This sample has an average value of 5.93, median value of 5 , and standard deviation of 3.34 . Accordingly, the suitable threshold value of number of accidents should be 6 . Any spot with more than 6 recorded injury accidents was considered a high accident frequency location. With this threshold as the criterion for identification, a total of 32 high accident frequency locations were determined. There were 302 injury accidents happened at 32 identified locations in three years, accounting for 52.86 percent of all injury accidents in the study area. 


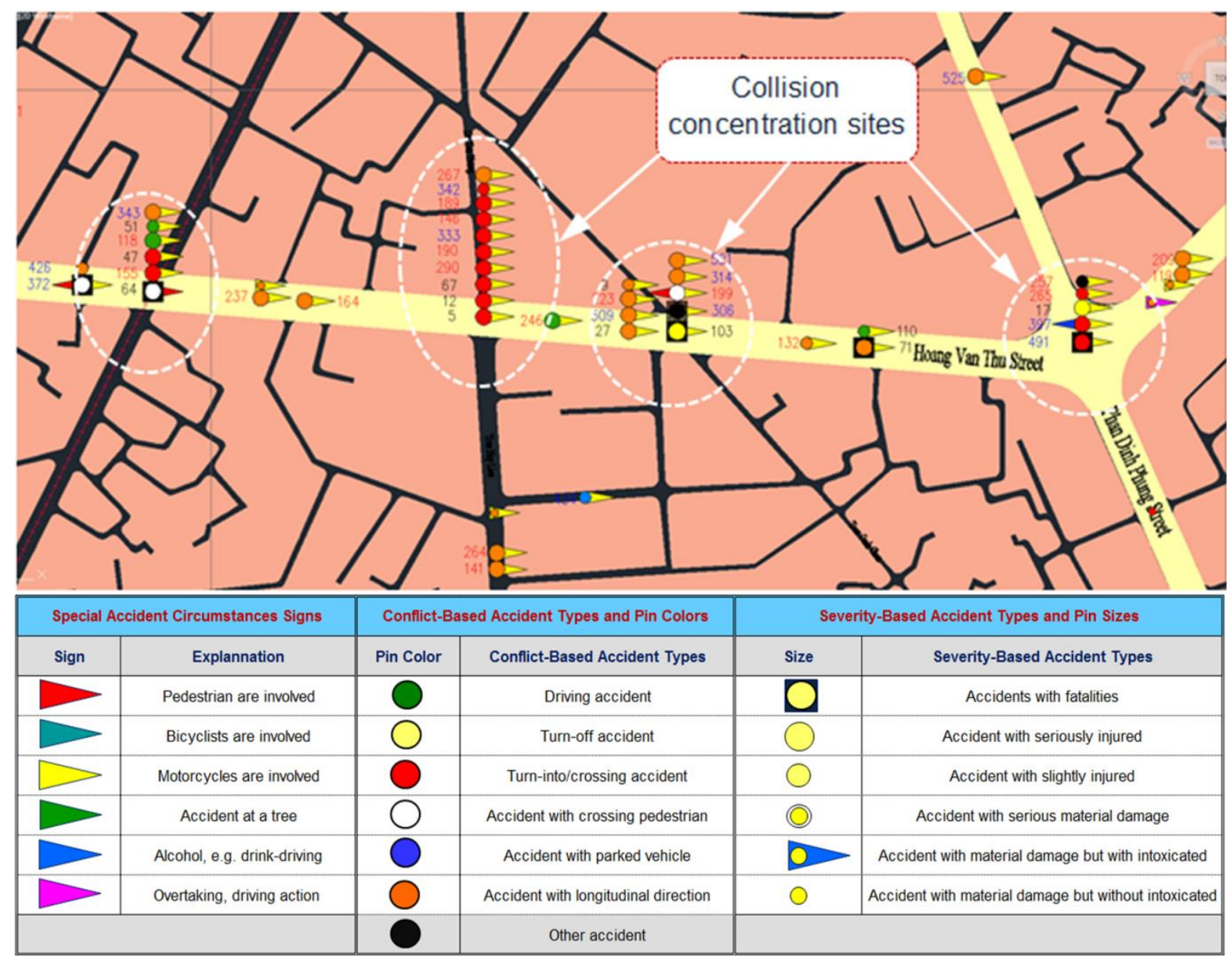

Fig. 2. Three-year Accident Pin Board of study area.

\subsubsection{Stage 4-Statistical test for high accident frequency locations}

This step was intended to estimate the percentage of random and systematic variation in accident count at each identified location. In order to have such estimation, it is necessary to calculate the confidence interval of the particular sample of accident count at each spot. The changes in observed accident numbers within the confidence interval form the systematic variation. The changes in observed number of accidents beyond the confidence interval form the random variation [29].

The occurrence probability of an observed accident value that is higher than the maximum value of the confidence interval can be calculated by using Poisson probability formula [1,27]. The percentage of random variation of accident count at a spot is calculated by Poisson cumulative probability as shown in Table 5 and Fig. 3.

The calculation method applied to the case of Spot S.002 as a typical one serves as the explanation for the calculation method applied to all other cases of 32 identified high accident frequency locations. The year-based numbers of recorded injury accidents at this spot in the years of 2009, 2010 and 2011 were 3, 4, and 3 respectively. These figures form a sample of 3 -year accident count whose long-term average value equals 3.33 . The $95 \%$ confidence interval of the sample was determined with 1.90 as the minimum value, and 4.77 as the maximum value. The determined interval indicates that the change in number of observed accidents from 2 accidents to 5 accidents is the real change or systematic variation. This systematic variation makes it possible to estimate the quantity of random variation of observed accidents at this spot by considering the year-based numbers of observed accidents were distributed pursuant to Poisson probability distribution. Specifically, for the case of a random variable $\mathrm{X}$ with the mean number of successes $(\mu)$ being 3.33 , the cumulative probability $\mathrm{P}(\mathrm{X} \geq 6,3.33)$ would be 0.1207 or $12.07 \%$. This value is the very random variation of observed accidents (see Table 5 and Fig. 3). 
Table 5. Statistical test for five typical high accident frequency locations.

\begin{tabular}{|c|c|c|c|c|c|c|c|c|c|c|}
\hline \multirow{2}{*}{ No. } & \multirow[t]{2}{*}{ Spot ID } & \multicolumn{4}{|c|}{ Observed Injury Accidents } & \multirow{2}{*}{$\begin{array}{l}\text { Long term } \\
\text { Average }\end{array}$} & \multicolumn{2}{|c|}{$95 \%$ Confidence Interval } & \multicolumn{2}{|c|}{$\begin{array}{l}\text { Poisson Cumulative Probability } \\
\qquad(\mathrm{X} \geq \mathrm{x}, \mu)\end{array}$} \\
\hline & & 2009 & 2010 & 2011 & Total & & Min & Max & Formula & Value \\
\hline 1 & S.002 & 3 & $\overline{4}$ & 3 & $\overline{10}$ & 3.33 & 1.90 & 4.77 & $\mathrm{P}(\mathrm{X} \geq 6,3.33)$ & 0.1207 \\
\hline 2 & S.003 & 4 & 3 & 3 & 10 & 3.33 & 1.90 & 4.77 & $\mathrm{P}(\mathrm{X} \geq 6,3.33)$ & 0.1207 \\
\hline 3 & S.010 & 5 & 4 & 3 & 12 & 4.00 & 1.52 & 6.48 & $\mathrm{P}(\mathrm{X} \geq 8,4.00)$ & 0.0511 \\
\hline 4 & S.011 & 4 & 2 & 3 & 9 & 3.00 & 0.52 & 5.48 & $\mathrm{P}(\mathrm{X} \geq 7,3.00)$ & 0.0335 \\
\hline 5 & S.012 & 2 & 3 & 3 & 8 & 2.67 & 1.23 & 4.10 & $\mathrm{P}(\mathrm{X} \geq 6,2.67)$ & 0.0544 \\
\hline
\end{tabular}

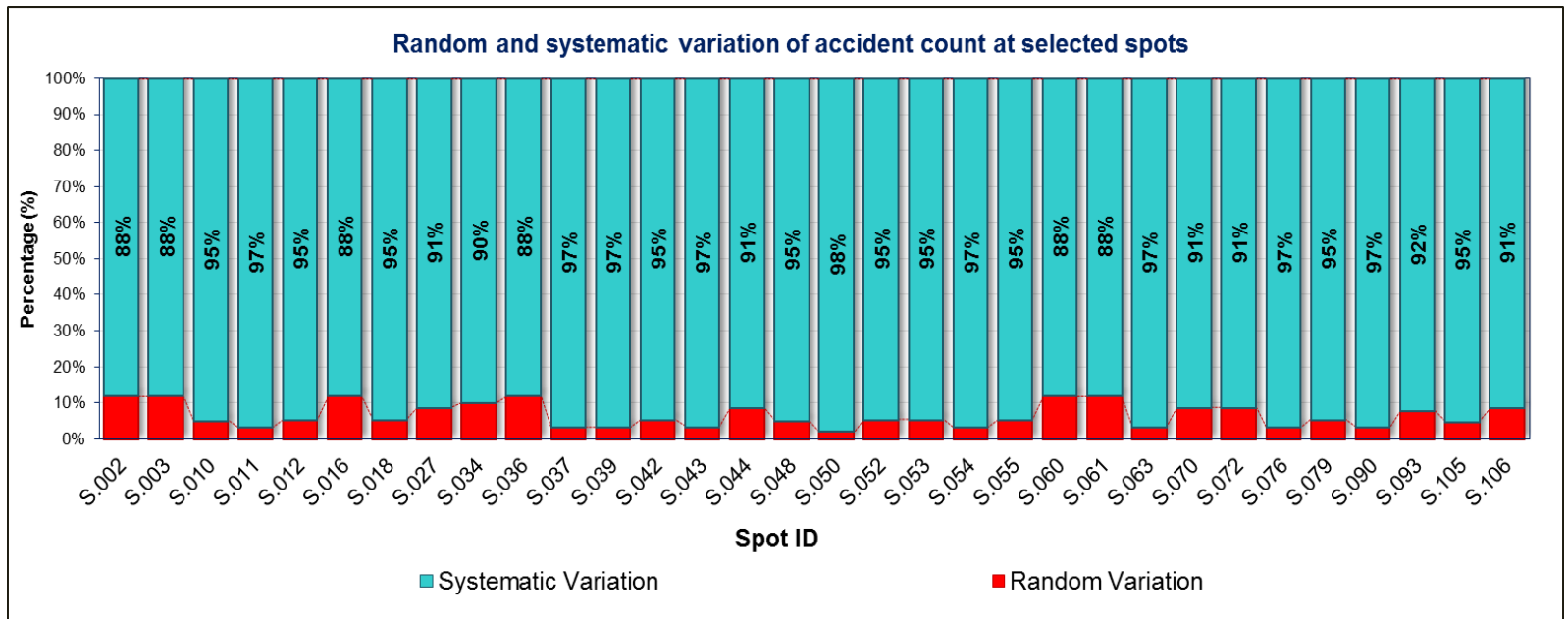

Fig. 3. Percentage of random and systematic variations of accident counts at 32 selected spots.

\subsubsection{Stage 5 - Calculating safety potential and ranking of spots}

The calculation of the safety potential and the ranking of spots according to their safety potential require a number of accident parameters as mentioned in Step 5 of the analytical framework. The results are shown in Fig. 4 and Table 6, in which the spots in were ranked by their safety potential in order to provide a priority list of spots to be treated $[14,28]$.

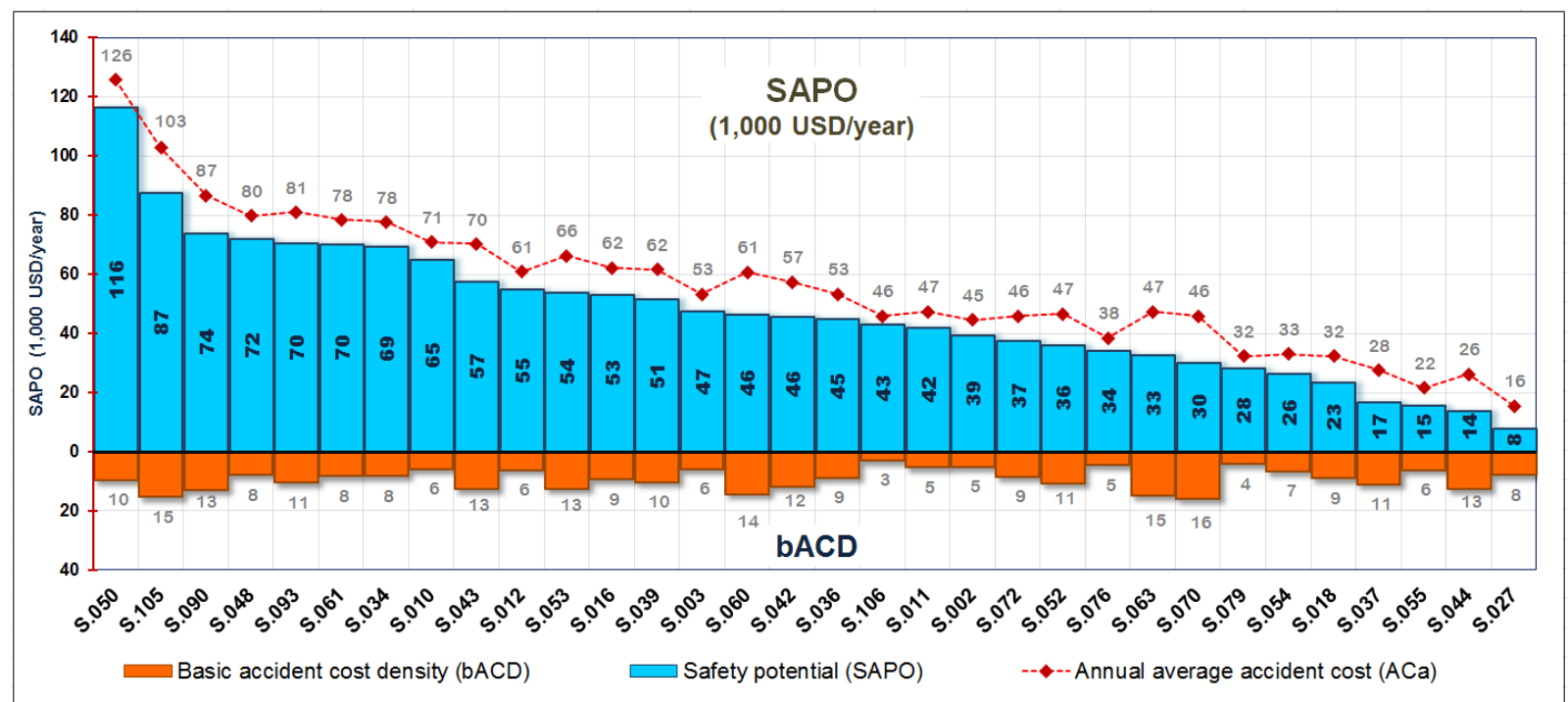

Fig. 4. Safety potentials of 32 selected spots within the road network (2009-2011).

Figure 4 shows that safety potential of a spot is the difference between actual accident cost and its expected accident cost of the spot. This expected value depends on the basic accident cost rate for a best- 
practice design. In this research, the value of basic accident cost rate was estimated from 15 percent of the overall distribution of accident cost rate of every specific type of spots.

The highest value of safety potential in Fig. 6 is 116,240 U.S. dollars per year. This means that each year at the spot, accident cost could be saved 116,240 U.S. dollars if it had a best-practice design. Therefore, if the cost of the safety countermeasure at the spot is given, the benefit-cost ratio of the safety improvement measure can be identified.

Furthermore, with the ranking of spots by safety potential, it is easy to decide which and how many spots to be treated depending on the financial resources. This fact adds new aspects to the concept of black spots and increases the flexibility of the selection of black spots to be treated by means of the prioritization which is based on economical effectiveness.

Table 6. Calculation of SAPO and ranking of the top 10 spots with highest SAPO.

\begin{tabular}{|c|c|c|c|c|c|c|c|c|c|c|c|c|c|c|}
\hline \multirow{2}{*}{ Spot ID } & \multirow{2}{*}{ ADT } & \multicolumn{4}{|c|}{ Accidents $(2009-2011)$} & \multirow{2}{*}{$\mathrm{AC}_{\mathrm{a}}$} & \multirow{2}{*}{$\mathrm{AD}$} & \multirow{2}{*}{ AR } & \multirow{2}{*}{ ACD } & \multirow{2}{*}{ ACR } & \multirow{2}{*}{ bACR } & \multirow{2}{*}{ bACD } & \multirow{2}{*}{ SAPO } & \multirow{2}{*}{ Ranking } \\
\hline & & $F$ & SI & LI & PDO & & & & & & & & & \\
\hline S.050 & 13,500 & 4 & 7 & 3 & 0 & 125,900 & 4.67 & 0.95 & 125.90 & 25.55 & 1.96 & 9.66 & 116.24 & 1 \\
\hline S.105 & 14,400 & 2 & 10 & 2 & 1 & 102,759 & 4.67 & 0.89 & 102.76 & 19.55 & 2.93 & 15.40 & 87.36 & 2 \\
\hline S.090 & 18,200 & 3 & 4 & 2 & 0 & 86,664 & 3.00 & 0.45 & 86.66 & 13.05 & 1.96 & 13.02 & 73.64 & 3 \\
\hline S.048 & 11,150 & 2 & 6 & 4 & 0 & 79,843 & 4.00 & 0.98 & 79.84 & 19.62 & 1.96 & 7.98 & 71.87 & 4 \\
\hline S.093 & 10,183 & 1 & 10 & 0 & 0 & 81,052 & 3.67 & 0.99 & 81.05 & 21.81 & 2.84 & 10.56 & 70.50 & 5 \\
\hline S.061 & 8,083 & 2 & 6 & 2 & 0 & 78,472 & 3.33 & 1.13 & 78.47 & 26.60 & 2.84 & 8.38 & 70.09 & 6 \\
\hline S.034 & 11,650 & 1 & 9 & 4 & 0 & 77,722 & 4.67 & 1.10 & 77.72 & 18.28 & 1.96 & 8.33 & 69.39 & 7 \\
\hline S.010 & 4,983 & 1 & 8 & 3 & 0 & 70,965 & 4.00 & 2.20 & 70.97 & 39.01 & 3.31 & 6.02 & 64.94 & 8 \\
\hline S.043 & 28,050 & 1 & 8 & 2 & 0 & 70,280 & 3.67 & 0.36 & 70.28 & 6.86 & 1.25 & 12.80 & 57.48 & 9 \\
\hline S.012 & 6,033 & 2 & 3 & 3 & 0 & 60,942 & 2.67 & 1.21 & 60.94 & 27.67 & 2.84 & 6.25 & 54.69 & 10 \\
\hline
\end{tabular}

\section{Summary}

This research presents a new black spot identification method which is expected to result in economic as well as societal benefits. In order to ensure these benefits, this new methods takes safety potential as its key parameter. With this key parameter, the method facilitates not only the identification but also the prioritization of black spots. Such facilitation, in its turn, enables the suitable selection of which black spots to treat first depending on the particular financial conditions of the given region or country.

In order to avoid unexpected shortcomings in the implementation of the method, it is important to pay special attention to the following two aspects.

First, safety potential is the difference between the actual accident cost and the expected accident cost conforming to the best-practice design standard. The expected accident cost depends on the basic accident cost rate. In ideal circumstances this expected accident cost contains no influence of the infrastructure on the accidents any more but represents the accident cost caused only by the other two components of the transport system - vehicle and road users. The best way to estimate the target values would be to calculate the accident cost rate for a sample of spots with best practice design. Another possibility would be to use a specific percentile of the overall distribution of the accident cost rates.

Second, statistical tests must be done to make sure that the random variation is not the decisive factor in the process of identifying the high accident frequency locations. Random variation in accident count at the identified locations can be estimated by Poisson probability distribution.

In conclusion, the method proposed in this research introduces a new aspect in black spot management by integrating prioritization into the identification. In this way, the method can optimize the black spot treatment with limited financial resources which are facing most developing countries. Still, the benefits are considerable in terms of economic efficiency. Therefore, the method is expected to be a satisfactory solution for accident reduction in developing countries.

\section{References}

[1] R. Elvik, "New approach to accident analysis for hazardous road locations," Transportation Research Record: Journal of the Transportation Research Board, no. 1953, pp. 50-55, 2006.

[2] S. F. Jafri, "An effective and way forward approach for road safety acquisition of knowledgeCorrelative study for pakistan," Engineering Journal, vol. 17, pp. 41-48, 2013. doi:10.4186/ej.2013.17.1.41 
[3] N. Norden, J. Orlansky, and H. Jacobs, "Application of statistical quality-control techniques to analysis of highway accident data," Highway Research Board Bulletin, no. 117, pp. 17-31, 1956.

[4] B. M. Rudy, "Operational route analysis," Highway Research Record Bulletin, no. 341, pp. 1-29, 1962.

[5] D. A. Morin, "Application of statistical concepts to accident data," Highway Research Record, no. 188, pp. 72-80, 1967.

[6] T. N. Tamburri and R. N. Smith, "The safety index: Method of evaluating and rating safety benefits," Highway Research Record, no. 332, pp. 28-39, 1970.

[7] N. O. Jorgensen, "Statistical detection of accident black spots," in Proc. of OTA-PLARC 11th International Study Week in Transportation and Safety, Brussels, Belgium, 1972.

[8] J. I. Taylor and H. T. Thompson, "Identification of hazardous locations," Report FHWA-RD, pp. $77-$ 81, 1977.

[9] D. R. D. Mcguigan, “The use of relationship between road accidents and traffic flow in 'black-spot' identification," Traffic Engineering and Control, pp. 448-453, 1981.

[10] D. R. D. Mcguigan, "Non-junction accident rates and their use in 'black-spot' identification," Traffic Engineering and Control, pp. 60-65, 1982.

[11] J. L. Higle and J. M. Witkowski, "Bayesian Identification of Hazardous Locations," Transportation Research Record 1185, TRB, National Research Council, Washington, D.C., pp 24-36, 1988.

[12] J. C. Overgaard Madsen, "Skadesgradsbasered sortpletudpeging-From crash prevention of loss reduction in the Danish Vejbestyrelsers," Ph.D. thesis, Traffic Research Group, Department of Development and Planning, Aalborg University, Aalborg, 2005.

[13] R. Elvik, "Comparative analysis of techniques for identifying locations of hazardous roads," Transportation Research Record: Journal of the Transportation Research Board, no. 2083, pp. 72-75, 2008 a.

[14] H. H. Nguyen, P. Taneerananon, C. Koren, and P. Iamtrakul, "Safety-potential-based black spot safety management approach: A case study in Ho Chi Minh City," Journal of the Eastern Asia Society for Transportation Studies, vol. 10, pp. 1991-2009, 2013.

[15] M. Habibian, M. Mesbah, and A. Sobhani, "Ranking of hazardous road locations in two-lane two-way rural roads with no crash record," in Australasian Transport Research Forum 2011 Proceedings, Adelaide, Australia, 2011.

[16] M. Mesbah and M. Habibian, "An approach for safety assessment of urban transportation networks," in Proc. $7^{\text {th }}$ International Congress on Civil Engineering, Tehran, Iran, 2006.

[17] W. Temrungsie, W. Raksuntron, N. Namee, S. Chayanan, and B. Witchayangkoon, "AHP-based prioritization on road accidents factors: A case study of Thailand," International Transaction Journal of Engineering, Management, Applied Sciences \& Technologies, vol. 6, pp. 135-144, 2015.

[18] Federal Highway Research Institute (Bast), Bergisch Gladbach, Germany, and Road Safety Director, Roads and Motorways Engineering Department (Sétra), Bagneux, France, "Network Safety Management - NSM," 08.06.2005.

[19] R. Elvik, "State-of-the-art approaches to road accident black spot management and safety analysis of road networks," RIPCORD-ISEREST - WP6, 2008b.

[20] W. Cheng and S. P. Washington, "Experimental evaluation of hotspot identification methods," Accident Analysis and Prevention, vol. 37, pp. 870-881, 2005.

[21] LTNZ, A New Zealand Guide to The Treatment of Crash Locations. Land Transport New Zealand 2004.

[22] K. W. Ogden, "Traffic engineering road safety: A practitioner's guide." A report prepared for the Federal Office of Road Safety, Department of Civil Engineering, Monash University, 1994.

[23] SEMCOG Traffic Safety Manual, 2nd ed, Southeast Michigan Council of Governments-SEMCOG 1997.

[24] Transportation Research Board-TRB, Highway Safety Manual, 1st ed. Washington, DC: Transportation Research Board, 2009.

[25] C. J. Baguley, "Interim guide on identifying, prioritising and treating hazardous locations on road in Malaysia," Jabatan Kerja Raya, JKR 20708-0022-95, Kuala Lumpur, 1995.

[26] R. Elvik, A. Høye, T. Vaa, and M. Sørensen, The Handbook of Road Safety Measures, $2^{\text {nd }}$ ed. Bradford, UK: Emerald Group, 2009.

[27] J. Kononov, "Identifying locations with potential for accident reductions-Use of direct diagnostics and pattern recognition methodologies," Transportation Research Record 1784, TRB, National Research Council, Washington, D.C., pp 153-158, 2002.

[28] N. Salatoom and P. Taneerananon, "A study of a flyover-bridge-Improved intersection," Engineering Journal, vol. 19, pp 1-12, 2015. DOI:10.4186/ej.2015.19.1.1 
DOI:10.4186/ej.2016.20.2.109

[29] R. Elvik, "Traffic safety," in Handbook of Transportation Engineering, M. Kutz, Ed. New York: McGrawHill, 2004, ch. 16. 